\title{
CONSIDERAÇÕES SOBRE A PROPOSTA DE PLANEJAMENTO REGIONAL NO EXTREMO SUL DE SANTA CATARINA: PROJETO GEOPARQUE CAMINHOS DOS CÂNIONS DO SUL
}

\section{CONSIDERATIONS ON THE PROPOSAL FOR REGIONAL PLANNING IN SANTA CATARINA SOUTH END: GEOPARK PROJECT WAYS OF SOUTH CANYONS}

\author{
Tarcisio Roldão da Rosa ${ }^{1}$ \\ Isa de Oliveira Rocha ${ }^{2}$ \\ Maria Paula Casagrande Marimon ${ }^{3}$
}

\section{RESUMO}

O objetivo do presente artigo consiste em apresentar algumas questões sobre o Projeto Geoparque Caminhos dos Cânions do Sul, que abrange o sul de Santa Catarina e o nordeste do Rio Grande do Sul. Neste território, em que a proposta do Geoparque está inserida, existem os Parques Nacionais de Aparados da Serra (PARNAS) e o Parque Nacional da Serra Geral (PNSG), vários sítios arqueológicos e paleontológicos e vinte Geossítios atestados pelo Serviço Geológico do Brasil (CPRM), entre outras unidades de conservação e potencialidades. Um Geoparque tem o propósito de desenvolver uma região no seu aspecto cultural, econômico e ambiental, tornando-se possibilidade de efetivação de um planejamento regional para alcançar o desenvolvimento socioambiental. A Secretaria do Desenvolvimento Regional de Araranguá (SDR/Araranguá) e a Associação dos Municípios do Extremo Sul Catarinense (AMESC), além de outras instituições, estão integradas em torno do objetivo de obter o título de Geoparque para o Extremo Sul de Santa Catarina.

Palavras-chave: Geoparque, Planejamento Regional, Sul Catarinense.

\section{ABSTRACT}

The purpose of this article is to present some questions about the Geopark Project Caminhos dos Cânions do Sul. In this territory of Geopark Project are the National Parks of the Aparados da Serra (PARNAS) and the National Park of Serra Geral (PNSG), archaeological and paleontological sites and twenty Geosites certified by the Serviço Geológico do Brasil (CPRM), among other potentials. A Geopark aims to develop the region as a cultural, economic and environmental aspect, making it the possibility of realization of a regional planning to achieve environmental development. The SDR and AMESC, and other institutions, are built around the goal of obtaining the title of Geopark to the South of Santa Catarina.

Keywords: Geopark. Regional Planning. South of Santa Catarina.

\footnotetext{
${ }^{1}$ Universidade do Estado de Santa Catarina - UDESC. Endereço: Avenida Madre Benvenuta, 2007 - Itacorubi, Florianópolis - SC, 88035-001. Telefone: (48) 3664-8000. E-mail: tarcisiocanyons@gmail.com

${ }^{2}$ Universidade do Estado de Santa Catarina - UDESC. E-mail: isa.rocha@udesc.br

${ }^{3}$ Universidade do Estado de Santa Catarina - UDESC. E-mail: paula.marimon@gmail.com
} 


\section{Introdução}

A implantação de um Geoparque tem a finalidade de desenvolver uma região no seu aspecto cultural, econômico e ambiental, em área que abranja determinado número de sítios geológicos peculiares. O projeto "Geoparque Caminhos dos Cânions do Sul”, proposto por setores da comunidade do Extremo Sul Catarinense necessita de avaliação e validação pela Rede Global de Geoparques da Unesco.

O objetivo do presente artigo, que é resultante dos estudos convergidos para a dissertação de mestrado desenvolvida no Programa de Pós-Graduação em Planejamento Territorial e Desenvolvimento Socioambiental da Universidade do Estado de Santa Catarina (UDESC), consiste em apresentar algumas reflexões sobre o Projeto Geoparque Caminhos dos Cânions do Sul. Neste território em que a proposta do Geoparque está inserida existem os Parques Nacionais de Aparados da Serra (PARNAS) e o Parque Nacional da Serra Geral (PNSG), sítios arqueológicos, paleontológicos e vinte Geossítios atestados pelo Serviço Geológico do Brasil (CPRM), entre outras unidades de conservação e potencialidades. (Figura $1)$.

A Secretaria do Desenvolvimento Regional de Araranguá (SDR/Araranguá) e a Associação dos Municípios do Extremo Sul Catarinense (AMESC), além de outras instituições locais, estão congregadas em torno de um foco em comum, obter o título de Geoparque, para assim alcançar maior dinamismo socioeconômico local, a ser impulsionado pela divulgação internacional através do Geoturismo. A dificuldade de consolidação do projeto Geoparque relaciona-se, principalmente, com a falta de um processo integrado de planejamento regional, pois a área abrange um total de 19 municípios do extremo sul catarinense e nordeste do Rio Grande do Sul. 
Figura 1- Geossítio Cânion Itaimbezinho, Parque Nacional de Aparados da Serra - SC/RS

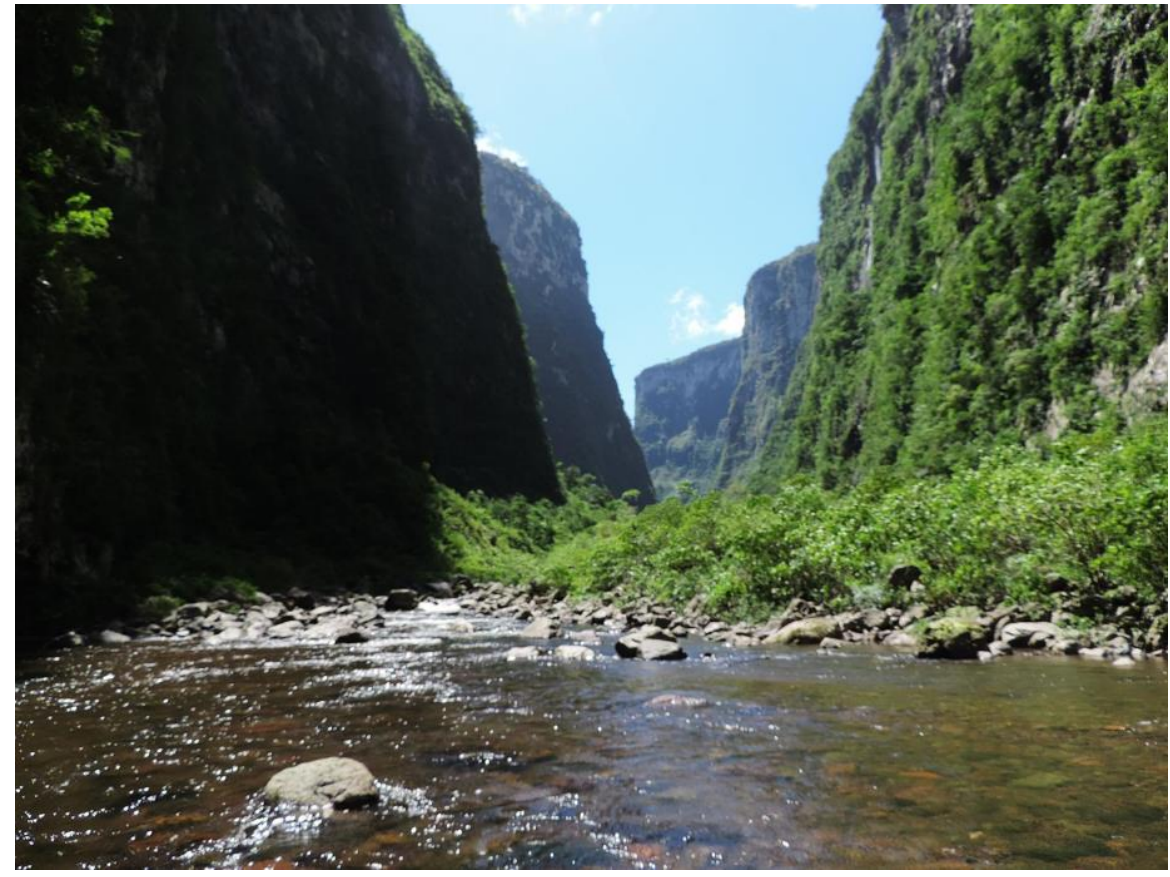

Foto: Tarcísio Roldão da Rosa

\section{Geoparque e Geoturismo}

Esta seção esclarece a nova categoria turística para o Brasil denominada de Geoturismo. Tal atividade se passa dentro de um Geoparque, uma área específica cujos elementos geológicos são supervalorizados. No entanto, outras condicionantes entram neste conjunto chamado Geodiversidade, levando-se em conta que tanto a vegetação como a fauna igualmente estão presentes nestas áreas singulares.

Segundo a Royal Society for NatureConservation do Reino Unido a Geodiversidade consiste na abundância de ambientes geológicos, fenômenos e processos ativos que dão origem as paisagens, desde as rochas, minerais, fósseis, solos e outros depósitos superficiais que são o suporte para a vida na Terra (BRILHA, 2005).

Geoparque é uma área com limites bem definidos e contendo um determinado número de sítios geológicos de importância científica, raridade e beleza, agregando valor arqueológico, econômico, histórico e cultural (UNESCO, 2009). O projeto Geoparque é reconhecido e avaliado pela Rede Global de Geoparques e UNESCO (Organização das Nações Unidas para a Educação, a Ciência e a Cultura).

O Geoparque é um segmento turístico emergente, que visa através da geodiversidade impulsionar economicamente uma determinada região, na qual ocorram sítios geológicos 
reconhecidos, como os geossítios. Geossítio segundo Brilha (2005):

\begin{abstract}
"é a ocorrência de um ou mais elementos da geodiversidade (aflorantes quer em resultado da ação de processos naturais quer devido à intervenção humana), bem delimitado geograficamente e que apresente valor singular do ponto de vista científico, pedagógico, cultural, turístico, ou outro".
\end{abstract}

A implantação de um Geoparque, como alternativa de desenvolvimento regional, poderá alavancar economicamente os municípios envolvidos, pois o aval da UNESCO traz o reconhecimento de que determinado território está contemplado com uma geodiversidade apta para visitação. O Geoparque deve contar coma instalação de painéis ilustrativos em todos os sítios geológicos, informando aos visitantes a história geológica daquele lugar, inclusive mencionando a referência de sítios paleontológicos e arqueológicos, se for o caso.

Certamente, se bem planejado, o Geoparque pode trazer grandes benefícios para as comunidades envolvidas, com a vinda de muitos turistas, pois o Geoturismo já é um ramo do turismo consolidado em outros países. Conforme Arouca (2011) "Geoturismo é compreendido como o turismo que sustenta e incrementa a identidade de um território, considerando a sua geologia, ambiente, cultura, valores estéticos, patrimônio e o bem-estar de seus residentes".

De acordo com Joana de Castro Rodrigues do Gabinete de Geologia e Paleontologia do Centro Cultural Raiano (GeoparkNaturtejo da Meseta Meridional - UNESCO Europeanand Global Geopark Idanha-a-Nova, Portugal):

antes de chegar ao geoturismo é necessário analisar diversas questões relacionadas com o património Geológico que estão na base deste conceito. É à sua volta que se desenrolam as variadas estratégias que conduzem o geoturismo. Não nos podemos esquecer de todas as particularidades deste tipo de património nem de todas as circunstâncias inerentes à sua conservação. São precisamente estes factores que vão ditar o tipo de actividades que poderão e deverão ser desenvolvidas (RODRIGUES, 2009).

Para que determinada região ateste seu potencial geológico no Brasil, e assim inicie este processo de construção de candidatura ao Geoparque, é necessário submeter-se ao 
Programa Geoturismo da CPRM (Serviço Geológico do Brasil). Este tem a finalidade de promover a caracterização física de regiões de interesse geoturístico, disseminando o conhecimento básico de geologia, informações geoambientais, geo-históricas e do patrimônio mineral existente entre as comunidades alcançadas (GLOBAL TURISMO, 2007).

No Brasil, pelo mapa a seguir (Figura 2), é visível o interesse existente pela implantação de Geoparques. Em 2014existiamcerca de 30 propostas de Geoparques aguardando aprovação no país.

Figura 2- Propostas de Geoparques no Brasil

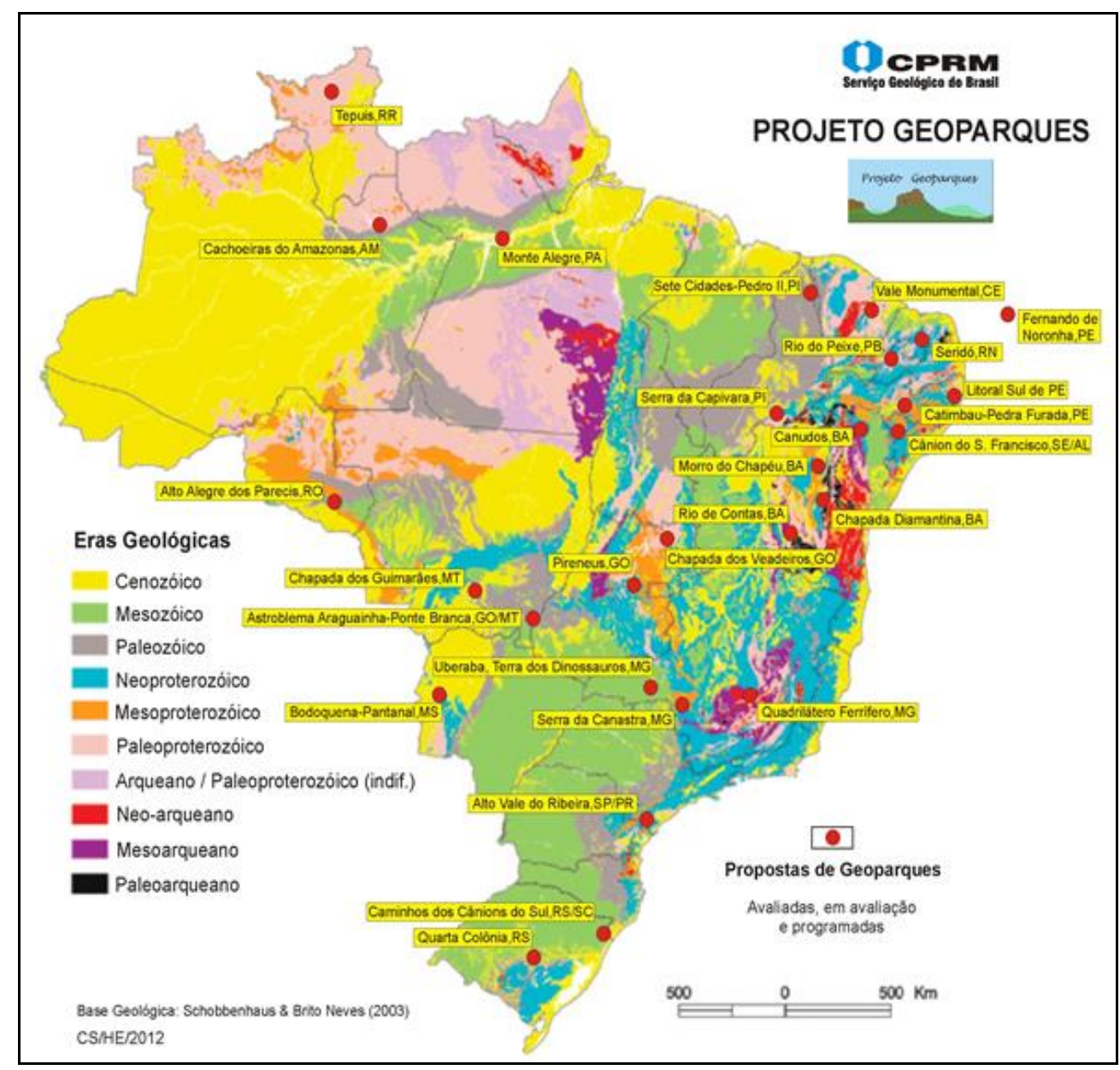

Fonte: http://www.cprm.gov.br/geoecoturismo/geoparque/canions/

Somente um Geoparque estava consolidado no Brasil até meados de 2015, é o Geoparque Araripe, localizado no Ceará. Em 2005, por iniciativa do Governo do Estado do Ceará, por meio da Secretaria de Ciência, Tecnologia e Educação Superior (SECITECE) e sob 
coordenação da Fundação Universitária Regional do Cariri (URCA), o Geoparque Araripe apresentou candidatura à Global Geoparks Network. Sua aceitação ocorreu em setembro de 2006, durante a II Conferência Internacional da UNESCO, sobre Geoparks em Belfast, na Irlanda do Norte (CATANA, 2008), tornando-se então membro da Rede Global de Geoparks. Localizado no sul do estado do Ceará, possui uma área de $3.520,52 \mathrm{~km}^{2}$ que compreende os territórios dos seguintes municípios: Crato, Juazeiro do Norte, Barbalha, Nova Olinda, Santana do Cariri e Missão Velha (SILVEIRA, 2012).

\section{Metodologia}

O presente artigo é resultado de pesquisa do tipo exploratória, qualitativa e interpretativa (GIL, 1996; MINAYO, 2009). Para tanto, efetuou-se amplo levantamento e análise documental e bibliográfica e visitas in loco para o registro de fotografias da área de estudo.

Logo no início dos trabalhos verificou-se que havia pouquíssimo material bibliográfico a respeito deste assunto, Geoparques no Sul do Brasil. Naquele momento, o material levantado consistiu em documentos informativos que tratavam da divulgação do Projeto Geoparque Caminhos dos Cânions do Sul, como livretos, panfletos, folders. As primeiras fontes de informações mais especializadas vieram dos coordenadores e professores que estavam divulgando tal projeto no Extremo Sul de Santa Catarina, os profissionais ligados diretamente à SDR, AMESC,IFC e IFSC. Além de informativos gerais sobre Geoparques, acessou-se os materiais próprios da rede global de geoparques (GGN - Geoparks Global Network) e assim analisou-se nas bibliografiaso modelo de parque - Geoparque - pela perspectiva europeia, a partir de autores renomados como o Geólogo José Brilha (2005), de Portugal, entre outros.

Em pesquisa na internet pôde-se averiguar que alguns artigos já estavam sendo publicados no Brasil por pesquisadores brasileiros. E, que alguns diagnósticos e relatórios estavam em pleno trabalho de execução e algumas pesquisas de discentes de programas de pós-graduação concluídas, destacando-se o estudo da Geóloga Flávia Lima (2008). Muitos destes trabalhos apresentados em seminários e congressos tiveram como motivação a implantação do Geoparque Araripe no Ceará, em 2006. A concretização deste Geoparque no Nordeste, como experiência nova no Brasil, resulta no esforço de pesquisadores brasileiros em publicar novos trabalhos sobre a temática. 
Observou-se que, à medida que surgiram as candidaturas de Geoparques por todo o território brasileiro, o interesse acadêmico se ampliou, e deste modo há novas pesquisas nesta concepção de parque no Brasil, resultando em recentes trabalhos científicos. Contudo, em bibliotecas universitárias não se encontra este tipo de obra, salvo algumas universidades que estão na vanguarda dos estudos.

Incluíram-se neste artigo algumas fotografias que pudessem representar alguns valores da paisagem presentes no contexto do geoparque como os cânion Itaimbezinho, cânion Fortaleza e cânion Monte Negro. Igualmente mapas produzidos pela CPRM (Serviço Geológico do Brasil) e quadros foram inseridos para ilustrara abrangência do território e organizar informações da proposta do Geoparque Caminhos dos Cânions do Sul.

Dentre as obras não referenciadas neste trabalho, mas que foram analisadas e apresentam importância para a continuidade dos estudos, destacam-se: o "Diagnóstico do território e recomendações para candidatura à Global Geoparks Network GGN" desenvolvida pela Geodiversidade Soluções Geológicas em fevereiro de 2013 e "Geodiversidade do Brasil, Conhecer o passado para entender o presente e prever o futuro" da CPRM (Serviço Geológico do Brasil) do Editor Geólogo MSc Cassio Roberto da Silva, de 2008.

\section{Resultados e Discussão}

Compreendidos os conceitos temáticos apresenta-se a seguir os fundamentos da proposta do Geoparque Caminhos dos Cânions do Sul como uma perspectiva de planejamento regional, ou seja, através do geoturismo desenvolver a sociedade, a economia e a cultura regional.

\subsection{Projeto Geoparque Caminhos dos Cânions do Sul (SC/RS)}

A proposta do Geoparque Caminhos dos Cânions do Sul surge para o Extremo Sul Catarinense a partir de 2006, quando se iniciam as discussões sobre a possibilidade de desenvolvimento por meio do Geoturismo. A região para a implantação do Geoparque está inserida nos territórios catarinense e rio-grandense, ou seja, no extremo sul de Santa Catarina e no nordeste do Rio Grande do Sul. A proposta abrange quatro municípios gaúchos (Torres, Mampituba, Cambará do Sul, São José dos Ausentes) e 15 municípios catarinenses (Araranguá, Balneário Arroio do Silva, Balneário Gaivota, Ermo, Jacinto Machado, Maracajá, Maleiro, Morro Grande, Passo de Torres, Praia Grande, Santa Rosa do Sul, São João do Sul, 
Sombrio, Timbé do Sul e Turvo); totalizando uma área de $5.670 \mathrm{~km}^{2}$ (Figura 3). (conforme material informativo da Secretaria de Desenvolvimento Regional de Araranguá)

Figura 3- Imagem da área de abrangência do Geoparque Caminhos dos Cânions do Sul $(\mathrm{SC} / \mathrm{RS})$

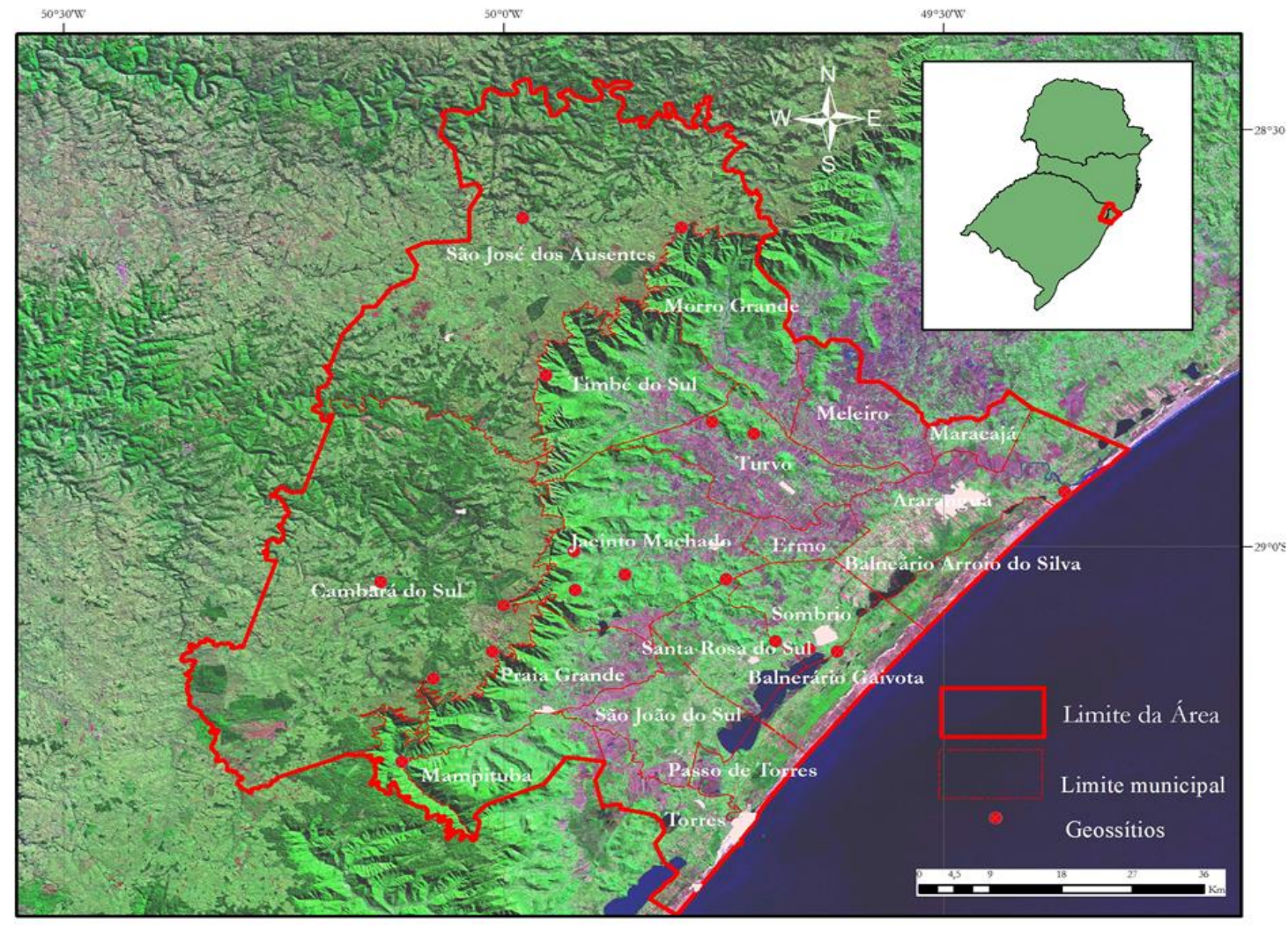

Fonte: http://www.cprm.gov.br/geoecoturismo/geoparque/canions/

$\mathrm{Na}$ área territorial da proposta do Geoparque Caminhos dos Cânions do Sul existem sítios geológicos importantíssimos, dentre os quais10 geossítios que estão sintetizados a seguir (Quadro 1) do total de 20 identificados (CPRM, 2011). 
Quadro 1- Principais geossítios da proposta do Geoparque Caminhos dos Cânions do Sul

\begin{tabular}{|c|c|c|c|c|}
\hline $\begin{array}{l}\text { Nome do } \\
\text { geossítio }\end{array}$ & Município & Terreno & Relevância & Possível utilização \\
\hline $\begin{array}{l}\text { Furnas de } \\
\text { Sombrio }\end{array}$ & Sombrio & Sedimentar & Regional & $\begin{array}{l}\text { Turística / Recreativa - } \\
\text { Pedagógica }- \text { Histórica / } \\
\text { Cultural }\end{array}$ \\
\hline $\begin{array}{l}\text { Morro } \quad \text { Três } \\
\text { Marias }\end{array}$ & Turvo & Sedimentar & Regional & Turística / Recreativa \\
\hline Morro Pelado & Turvo & Sedimentar & Regional & $\begin{array}{lll}\text { Turística / Regional - } \\
\text { Pedagógica } & & \end{array}$ \\
\hline $\begin{array}{l}\text { Furnas Índios } \\
\text { Xocleng }\end{array}$ & Jacinto Machado & Sedimentar & Regional & $\begin{array}{l}\text { Turística / Recreativa - } \\
\text { Científica - Pedagógica - } \\
\text { Histórica / Cultural }\end{array}$ \\
\hline Morro Carasal & Jacinto Machado & $\begin{array}{l}\text { Sedimentar } \\
\text { Vulcânico }\end{array}$ & Regional & Científica / Turística \\
\hline $\begin{array}{l}\text { Morro dos } \\
\text { Conventos }\end{array}$ & Araranguá, & Sedimentar & Regional & $\begin{array}{l}\text { Turística / Recreativa - } \\
\text { Científica, Pedagógica - } \\
\text { Histórica / Cultural }\end{array}$ \\
\hline $\begin{array}{l}\text { Cânion da } \\
\text { Pedra }\end{array}$ & $\begin{array}{l}\text { Jacinto Machado / } \\
\text { Cambará do Sul }\end{array}$ & Vulcânico & Regional & $\begin{array}{l}\text { Científica / Turística / } \\
\text { Recreativa - Pedagógica }\end{array}$ \\
\hline Pedra Branca & $\begin{array}{l}\text { Mampituba/Praia } \\
\text { Grande }\end{array}$ & $\begin{array}{l}\text { Sedimentar / } \\
\text { Vulcânico }\end{array}$ & Regional & $\begin{array}{l}\text { Turística /Recreativa } \\
\text { Histórica / Cultural }\end{array}$ \\
\hline $\begin{array}{l}\text { Cânion } \\
\text { Itaimbezinho }\end{array}$ & $\begin{array}{l}\text { Praia Grande } \\
\text { Cambará do Sul }\end{array}$ & Vulcânico & Internacional & $\begin{array}{l}\text { Turística / Recreativa - } \\
\text { Científica - Pedagógica - } \\
\text { Histórica - / Cultural }\end{array}$ \\
\hline $\begin{array}{l}\text { Mirante da } \\
\text { Lagoa }\end{array}$ & $\begin{array}{l}\text { Sombrio, Santa Rosa } \\
\text { do Sul }\end{array}$ & Sedimentar & Regional & $\begin{array}{l}\text { Turística / Recreativa - } \\
\text { Científica - Pedagógica }\end{array}$ \\
\hline
\end{tabular}

Fonte: CPRM (2011)

A beleza cênica da região a ser incorporada ao Geoparque Caminhos dos Cânions do Sul se estende desde o litoral, região aplainada e de baixa altitude, até a serra gaúcha e catarinense no planalto (Figura 4). Entre o mar e o planalto está a Serra Geral, como parte da linha de divisa entre os dois estados do Sul. 
Figura 4 - Modelo Digital do Terreno e limites municipais e estaduais - Geoparque Caminhos dos Cânions do Sul (SC/RS)

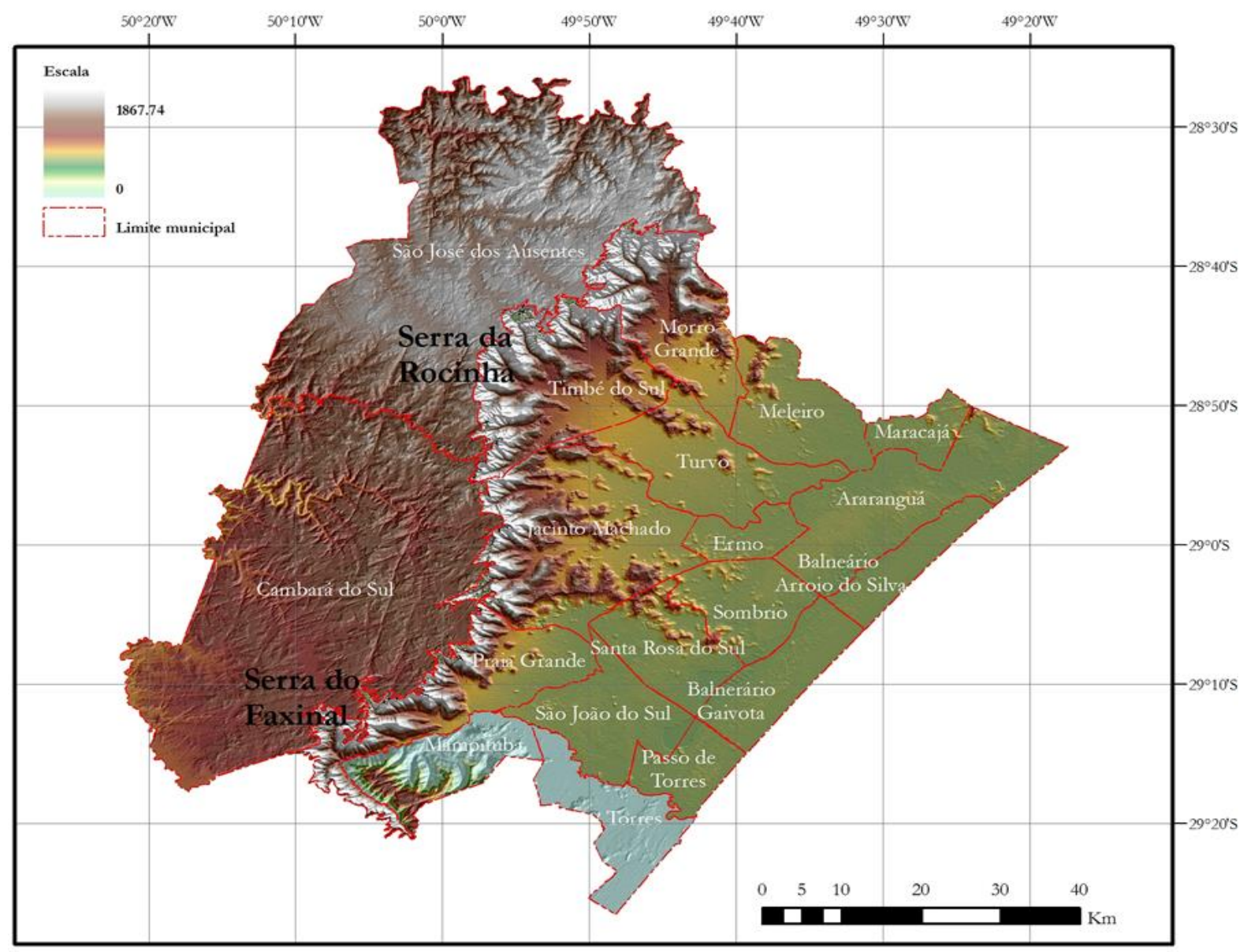

Fonte: http://www.cprm.gov.br/geoecoturismo/geoparque/canions/

A Secretaria do Desenvolvimento Regional de Araranguá (SDR/Araranguá) e a Associação dos Municípios do Extremo Sul Catarinense (AMESC), entre outras instituições, vislumbraram nesta proposta de Geoparque uma oportunidade de alavancar o desenvolvimento socioeconômico da região através do turismo geológico. Alguns profissionais, como professores de Geografia e Geologia de instituições locais, mostram-se interessados e participativos neste processo de implantação. Para tanto, são organizadas reuniões, palestras e cursos que visam estimular e informar principalmente os profissionais da área do turismo, bem como demais interessados das comunidades envolvidas.

Destaca-se o curso de capacitação "Aspectos da Geologia e Geomorfologia do Geoparque Caminhos dos Cânions do Sul”, realizado na cidade de Praia Grande (SC), no período de 15/10 a 12/11/2013, organizado com conteúdos de Geologia e Geomorfologia, 
além de visitas a alguns geossítios de extrema importância para a consolidação do Geoparque. O curso ocorreu como parceria entre o IFSC (Instituto Federal de Educação, Ciência e Tecnologia) e o Ministério da Educação e promovido pelo IFC - Campus Sombrio; AMESC, IFSC - Campus Araranguá, Prefeitura Municipal de Praia Grande e SDR/Araranguá.

O Geoparque Caminhos dos Cânions do Sul insere-se na porção Sudeste do Planalto Meridional, que compõe o Planalto Brasileiro, segundo a classificação do geógrafo Aziz NacibAb'Saber para o relevo brasileiro. Para melhor caracterização, o Planalto Meridional, que ocupa a porção Sul do país, assim se caracteriza:

No Planalto Arenito-basáltico, há cerca de 145.000.000 anos atrás, em área onde atualmente está a região Sul do país, tinha-se um ambiente desértico, no qual os ventos transportavam a areia e formavam grandes dunas, que com o passar do tempo originaram as rochas denominadas de arenitos. Neste ambiente, quando a África ainda estava junto com a América do Sul, entre outras partes continentais, formando o continente Gondwana, imensos falhamentos foram abertos pela movimentação e rompimento do terreno desse antigo continente. Destes falhamentos, de tempos em tempos, erupcionavam grande quantidade de lavas vulcânicas, que se espalhavam sobre os novos continentes que se afastavam. Quando estas erupções cessavam, as lavas resfriavam e solidificavam, formando as rochas desde a composição de basaltos até riodacitos, que recobriam, a base da sequência, as areias do deserto. Essas rochas vulcânicas é que sustentam o planalto sul brasileiro que é composto na base por camadas de arenito (mais friáveis), sobrepostas por basaltos e riodacitos (mais resistentes). As diferentes resistências dessas rochas permitiram que os rios da região escavassem muitos vales, com muitas cachoeiras. A deposição ocorreu com leve inclinação na direção da calha do Rio Paraná (a oeste), originando um relevo de cuestas, formas típicas desse planalto, e que recebe a denominação de Serra Geral, que seria a zona de contato com a denominada Depressão Periférica.

A parte catarinense da proposta do Geoparque é acentuada por escarpas, vales profundos que recortam toda a borda do planalto e uma planície arenosa quaternária, entremeada de lagoas, que se estende até o mar. Na parte rio-grandense (da proposta de Geoparque) domina o planalto, com relevo caracterizado por coxilhas suaves e vales rasos que se aprofundam em degraus súbitos, formando sucessivas quedas d'água, a medida que os rios e arroios se encaixam em vales estreitos e de encostas íngremes, ou mesmo, em verdadeiros cânions. O planalto termina abruptamente para leste, sem transição, dando lugar a 
paredões quase verticais (as cuestas). A denominação de "Aparados da Serra" vem da ocorrência nas partes altas do planalto de campos sempre desbastados pelo ventos, indicando a ocorrência de fortes ventos na área. A borda do planalto é recortada mais ou menos profundamente por cânions. Em alguns lugares, ao contrário, o planalto prolonga-se em morros isolados ou forma serras que descem gradualmente até a planície quaternária adjacente. (Figuras 5 e 6 )

Figura 5- Geossítio Cânion Monte Negro, Serra Geral - SC/RS

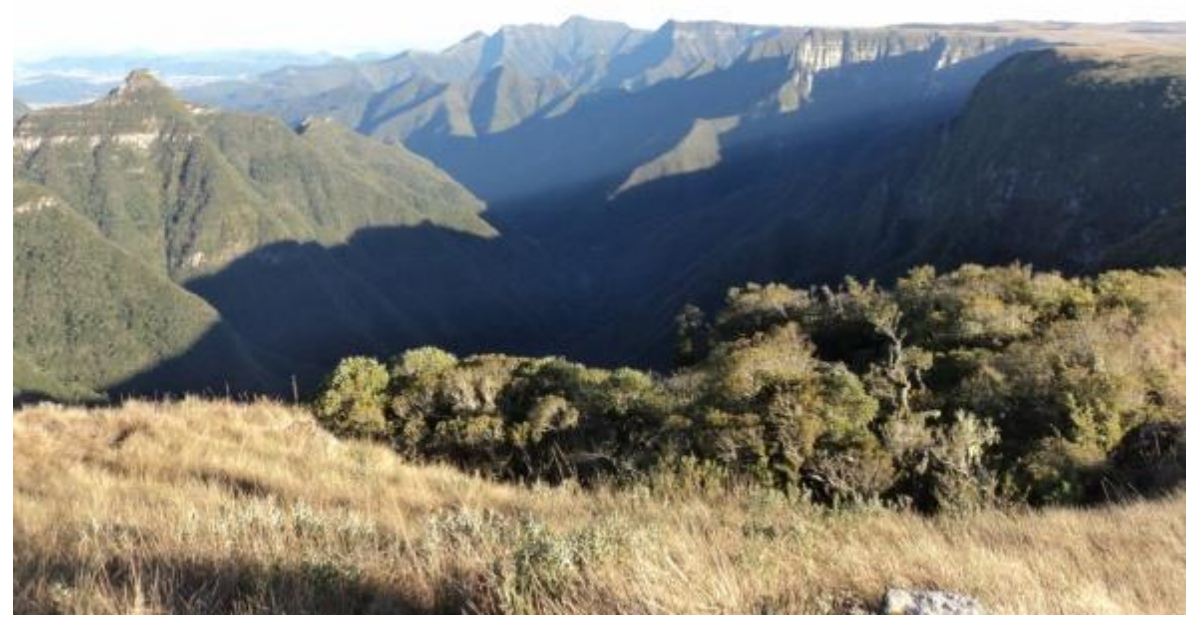

Foto: Tarcísio Roldão da Rosa 
Figura 6 - Geossítio Cânion Fortaleza, Jacinto Machado - SC

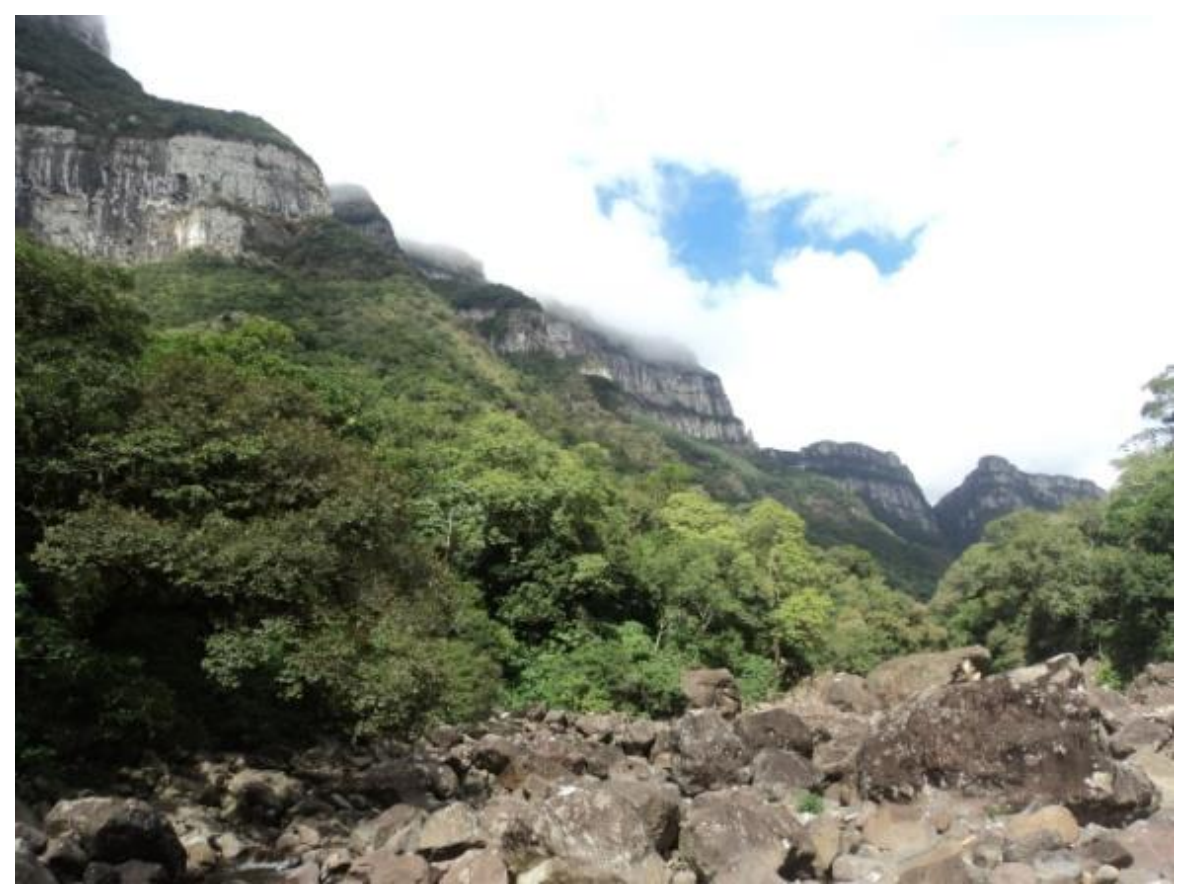

Foto: Tarcísio Roldão da Rosa

De acordo com o material informativo da CPRM (2012) as potencialidades descritas são muitas no Geoparque Caminhos dos Cânions do Sul, como por exemplo:

a) Os maiores cânions da América Latina; b) Parques Nacionais de Aparados da Serra e Serra Geral, Reserva da Biosfera da Mata Atlântica, APA Rota do Sol, Parques Estaduais de Tainhas, Itapeva e Guarita e Parque Ecológico Municipal de Maracajá; c) Praias, lagos, dunas, rios, falésias, mirantes, furnas, trilhas e belezas cênicas; d) Pluralidade de atrativos culturais com rico calendário festivo e gente hospitaleira; e) Turismo rural, ecológico, de aventura, de contemplação, científico, cultural, dentre outros; f) Elementos geológicos que contam o passado da Terra e da Vida que representam ricos materiais para o estudo científico e locais de contemplação que nos permitem refletir sobre o presente com outras perspectivas, especialmente, em relação ao futuro sustentável; g) Diversidade cultural, biodiversidade e geodiversidade; h) Sítios arqueológicos, paleontológicos e 20 Geossítios atestados pelo Serviço Geológico do Brasil. 


\subsection{Geoparque e planejamento regional}

O projeto do Geoparque Caminhos dos Cânions do Sul se insere, também, num contexto de proposição de planejamento regional. Para melhor descrever a região, que se situa na divisa entre os dois estados do Sul (Santa Catarina/Rio Grande do Sul), deve-se levar em consideração a perspectiva de estudo dos aspectos da natureza como também do quadro da sociedade. Para que esta região se desenvolva economicamente, socialmente e culturalmente é necessário inicialmente realizar um diagnóstico regional do quadro da natureza, da sociedade e da principal problemática socioambiental existente (MAMIGONIAN, 1999; AGUIAR, 1997 apud ROCHA et al.,2012).

Destaca-se aqui a concepção de desenvolvimento assumida:

acesso físico e econômico (condições materiais de vida) aos bens, serviços e equipamentos que permitem a satisfação das necessidades básicas, nelas se compreendendo, entre outras, a habitação, o emprego, a educação, o lazer, a saúde e o bem-estar, como oportunidades de benefício, mas também de participação ativa na construção da coesão social (MAFRA; SILVA, 2004).

A Proposta Metodológica de Análise Socioeconômica para Estudos Ambientais e de Reordenamento Territorial (IBGE) procura entender "a vida em sociedade de forma global" (AGUIAR, 1997), evitando privilegiar um ou outro dado econômico, compreendendo-se que as necessidades de todos os cidadãos devem ser absorvidas na análise para serem satisfeitas. Para que se consolide esta preocupação é adotada como premissa:

A compreensão da realidade por etapas; a abordagem holística; a linguagem interdisciplinar e a noção de desenvolvimento centrado na satisfação das necessidades individuais e coletivas, com menor agressão ambiental possível. Esta concepção apoia suas avaliações em novos critérios, onde prevalecem as noções de equidade, ética, harmonia e consciência social. (AGUIAR, 1997)

Neste ponto, nota-se que o "todo" é uma linguagem comum aplicada como método, que compreende as seguintes etapas, conforme Aguiar (1997): Caracterização, Levantamento 
de Problemas Socioambientais, Hierarquização de Problemas, Sínteses Socioeconômicas, Zoneamento Ambiental e Subsídios ao Reordenamento Territorial.

Corrobora com tal perspectiva Grinover:

A preocupação fundamental do planejamento e da organização do Estado refere-se à reorientação do estilo de desenvolvimento, dirigida para a satisfação das necessidades básicas da população em geral e para o desenvolvimento sustentável a longo prazo, bem como para a ampla participação da população em todos os níveis (GRINOVER, 1989).

Seria impossível, diante deste raciocínio, desarticular o homem de seu espaço de trabalho e do ambiente natural em que vive, ou seja, é necessário atentar para as questões ambientais:

O planejamento territorial (regional e urbano), já há algum tempo operando com indicadores econômicos e sociais e utilizando-se de outras disciplinas, deve introduzir agora novos indicadores, como os ambientais, para adquirir uma série de elementos de base que lhe permitam um conhecimento adequado dos níveis de produtividade, unicidade e qualidade ambiental dos ecossistemas que estruturam a função territorial (GRINOVER, 1989).

Conforme PNOT (2006) o “Ordenamento Territorial é a regulação das ações que têm impacto na distribuição da população, das atividades produtivas, dos equipamentos e de suas tendências". O Planejamento Territorial (regional e urbano) pode ser definido como "o melhor meio de ocupar um sítio ou região, prever os pontos onde se localizarão atividades, e todos os usos do espaço, presentes e futuros" (Ministério das Cidades). Neste sentido, preveem-se as atividades da região e as intervenções para preservar/conservar o patrimônio natural, a identidade social, cultural, educacional etc.

O Geoparque, talvez, não seja a solução imediata de desenvolvimento socioambiental regional para o Extremo Sul Catarinense, porém se mostra como uma oportunidade a mais de incluir todos os setores da sociedade local no debate sobre as possibilidades viáveis existentes. Mas, obviamente, trata-se de um processo contínuo, e nos objetivos basilares de uma proposta de Geoparque aparece a meta de preservar para 
desenvolver. Isto é, certas áreas necessitam se manter intactas para o presente e para o futuro, pois além de constituírem-se em opções de atividade turística, são objeto de pesquisas científicas. Outros locais disponíveis podem acomodar a instalação de atividades econômicas diversificadas, possibilitando a geração de renda para a população.

A proposta do Geoparque Caminhos dos Cânions do Sul vai se consolidando aos poucos como uma nova possibilidade de renda e emprego na região do Extremo Sul Catarinense e Nordeste Rio-Grandense, uma opção a mais para uma economia tipicamente agrícola (fumo, arroz e mandioca) e industrial (BELTRÃO, 2013).

\section{Considerações finais}

Os órgãos que regulamentam os Geoparques ou que pelo menos atestam a qualidade geológica de uma região no Brasil são a CPRM (Serviço Geológico do Brasil) e a Rede Global de Geoparques (Global Geoparks Network - GGN), sob os auspícios da UNESCO. Sem os estudos e pareceres destes órgãos não é possível montar o Plano de Trabalho e o Dossiê de Candidatura, pois acima da vontade política, está a questão técnico-científico necessária para a criação de um Geoparque.

A região do Geoparque Caminhos dos Cânions do Sul está compreendida na denominada Bacia do Paraná, que recobre não somente a região Sul, mas ocorre desde o Mato Grosso no Brasil, e abrange parte da Argentina, do Paraguai e do Uruguai, bem como da África. O vulcanismo aqui encontrado ocorreu no Cretáceo inferior resultante da separação do continente da Gondwana e abertura do oceano Atlântico. A Serra Geral é como se fosse uma vitrine exposta de parte da história geológica da Terra, principalmente do vulcanismo Serra Geral, destacada nos paredões dos cânions profundos e longos. A força das águas durante milhões de anos somados à erosão e intemperismo deu conta de abrir e ampliar cada vez mais os cânions. Esta paisagem singular acrescida de geossítios também localizados na área de planície quaternária, próxima ao mar, constitui uma região especial para a criação de um Geoparque no Sul do Brasil.

Mas, até o momento, há somente registros tímidos do envolvimento do setor político do Extremo Sul Catarinense na execução desta proposta de planejamento regional. Contudo, observa-se a mobilização de vários profissionais, principalmente da área da geografia (professores) para a viabilidade da proposta. Ainda, verificou-se a necessidade de encaminhamentos basilares, como por exemplo: a) os trâmites legais para o Processo de 
Construção da Candidatura, o Plano de Trabalho e o Dossiê de Candidatura visando a consolidação e reconhecimento do Geoparque catarinense e gaúcho; e b) a necessidade de desenvolvimento de um relatório de diagnóstico socioambiental regional, englobando todos os municípios envolvidos pelo Geoparque.

Tal diagnóstico socioambiental regional certamente deve incorporar nas suas análises, conforme Rocha et al. (2012) alicerçados em Mamigonian (1999), a perspectiva de Geossistema conforme Veado (2014) e Formação Sócio-Espacial conforme Santos (1977), pois a constituição regional em foco é consequência da inter-relação entre o quadro natural e a evolução social, econômica e espacial.

Conforme Santos (1977) apud Rocha et al. (2012): "Modo de produção, formação social, espaço [...] são interdependentes”. O território regional em questão, como recorte espacial, "seria o conjunto do trabalho morto (formas geográficas) e do trabalho vivo (contexto social) [...] O espaço é igual à paisagem mais a vida nela existente; é a sociedade encaixada na paisagem, a vida que palpita conjuntamente com a materialidade" (SANTOS, 1994).

A sociedade se desenvolve na superfície terrestre, no espaço, que "deve ser tomado como encontro do social e do natural; como sociedade, que implica na relação orgânica entre homem/natureza e como natureza, que existe independente do homem" (VIEIRA, 2009; apud ROCHA et al., 2012).

Igualmente ao longo da realização do diagnóstico devem-se analisar os conflitos socioambientais existentes objetivando a busca de possíveis soluções. Apoiado na proposta de Aguiar et al. (1997) o artigo de Rocha et al. (2012) destaca:

"que o desenvolvimento deve buscar a satisfação das necessidades individuais e coletivas, em nível do cidadão e de cada segmento que compõe a sociedade, denominados de pontos de vista (agricultura, comércio, indústria etc.), [e para tanto] é fundamental o levantamento de problemas socioambientais." 
Por fim, cabe aqui lembrar:

\begin{abstract}
Mais do que simples espaços territoriais os povos herdaram paisagens e ecologias, pelas quais certamente são responsáveis, ou deveriam ser responsáveis. Desde os mais altos escalões do governo e da administração até o mais simples cidadão, todos têm uma parcela de responsabilidade permanente, no sentido da utilização não-predatória desta herança única que é a paisagem terrestre (AB'SABER, 2003).
\end{abstract}

\title{
REFERÊNCIAS
}

AB'SABER, Aziz N. Os domínios de natureza no Brasil: potencialidades paisagísticas. São Paulo: Ateliê Editorial, 2003.

AGUIAR, Tereza. C. et al.. Uma proposta metodológica de análise socioeconômica para estudos ambientais e de reordenamento territorial. Rio de Janeiro: IBGE, 1997.

AROUCA GEOPARK (Portugal). O Congresso Internacional de Geoturismo "Geotourism in Action - Arouca 2011",Portugal, 9 a 13 de Novembro de 2011.

BELTRÃO, Leila Maria V. A industrialização em Sombrio/SC: gênese e evolução. Dissertação (Mestrado em Geografia). Centro de Filosofia e Ciências Humanas. Universidade Federal de Santa Catarina, Florianópolis, 2001.

BELTRÃO, Leila Maria V. A industrialização em pequenos municípios do sul de Santa Catarina - Notas teóricas e metodológicas. X ENANPEGE - Geografias, Políticas Públicas e Dinâmicas Territoriais, 7 a 10 de outubro de 2013.

BRILHA, J.B. Património Geológico e Geoconservação: a conservação da natureza na sua vertente geológica. Palimage Editores, Viseu, 2005.

CATANA, M. M. D. S. Valorizar e Divulgar o Patrimônio Geológico Naturtejo. Estratégias para o Parque Icnológico de Penha Garcia. Dissertação (Mestrado em Patrimônio Geológico e Geoconservação). Universidade de Minho, Braga, 2008.

CHOLLEY, A. Observações sobre alguns pontos de vista geográficos. Boletim Geográfico. Rio de Janeiro: CNG, n.179 e 180, 1964.

GIL, Antonio Carlos. Como Elaborar Projetos de Pesquisa. $3^{\text {a }}$ ed. São Paulo. Editora Atlas S.A., 1996.

GLOBAL TOURISM. Periódico de Turismo. Geoturismo: Um novo segmento do turismo no Brasil. Vol. 3, n 2, Nov. 2007. 
GRINOVER, Lucio. O planejamento físico-territorial e a dimensão ambiental. Cadernos FUNDAP. São Paulo, Ano 9,n. 16, jun./1989.

MAFRA, Francisco; SILVA, J. Amado da. Planejamento e Gestão do Território. Porto: Sociedade Portuguesa de Inovação, 2004.

MAMIGONIAN, Armen. A geografia e “A formação social como teoria e como método". In: Souza, Maria Adélia A. de (org.). O Mundo do Cidadão - Um Cidadão do Mundo. São Paulo:

Hucitec, 1996.

$\frac{1}{1999 .}$. Tendências atuais da Geografia. Geosul. Florianópolis: Editora da UFSC, n. 28, v. 14,

MATERIAL INFORMATIVO. SDR - 22 ${ }^{\mathbf{a}}$ Secretaria do Estado do Desenvolvimento Regional - Araranguá, SC. 2012.

MINAYO, Maria C. de S. (Org.). Pesquisa Social: teoria, método e criatividade. Petrópolis, RJ: Vozes, 2009.

PELUSO JÚNIOR,Victor A. Aspectos geográficos de Santa Catarina. Florianópolis: FCC/EDUFSC, 1991.

PNOT. Documento base para a definição de uma Política Nacional de Ordenamento Territorial. Projeto "Elaboração de subsídios técnicos e documento-base para a definição da Política Nacional de Ordenação do Território - PNOT”. Brasília: Ministério da Integração Nacional, 2006.

RELATÓRIO CPRM - Proposta do Geoparque Caminhos dos Cânions do Sul. Disponível em: <http://www.cprm.gov.br/geoecoturismo/geoparques/canions/>. Acessado em maio/2014.

ROCHA, I. O.; MARIMON, M. P. C.; DAL SANTO, M. A.; VEADO, R. W. Adv. Planejamento e Desenvolvimento Regional: proposição teórico-metodológica aplicada na região da Grande Florianópolis (SC) In: Anais do $1^{\circ}$ Seminário de Desenvolvimento Regional, Estado e Sociedade - SEDRES. Rio de Janeiro: SEDRES/ANPUR, 2012.

RODRIGUES, J. C. Geoturismo e Desenvolvimento Local. In: Neto de Carvalho, C. and Rodrigues, J.. Geotourism\& Local Development. Idanha-a-Nova, 2009. Disponível em: $<$ file:///C:/Users/Usuario/Desktop/geotourism_and_local_development.pdf $>$. Acessado em: junho de 2014.

SANTA CATARINA. GAPLAN. Atlas de Santa Catarina. Rio de Janeiro: Aerofoto Cruzeiro, 1986

SANTOS, Milton. Sociedade e espaço: a formação social como teoria e como método. Boletim Paulista de Geografia. n. 54. São Paulo: AGB/FFLCH-USP, 1977. 
. Metamorfose do espaço habitado. Fundamentos teóricos e metodológicos de geografia. São Paulo: Hucitec, 1994.

SilveirA, A. C., Silva, A. C., CABRAL, N. R. A. J., SCHIAVETTI, A. Análise de Efetividade de Manejo do Geopark Araripe - Estado do Ceará. Geociências. São Paulo, UNESP, v. 31, 2012.

UNESCO. Guidelines and Criteria for National Geoparks seeking UNESCO's assistance to join the Global Geoparks Network, 2006.

VEADO, Ricardo W. ad-Víncula. Capítulo 1 - Geossistemas de Santa Catarina. In: ROCHA, Isa de Oliveira (Org.). SANTA CATARINA. Secretaria de Estado do Planejamento. Atlas Geográfico de Santa Catarina: Diversidade da Natureza - Fascículo 2. 1. ed. Florianópolis: Editora UDESC, 2014.

VIEIRA, Maria G. E. de D. Considerações a respeito do paradigma de formação sócioespacial. Anais do $\mathbf{1 2}^{\circ}$. Encontro de Geógrafos da América Latina. Montevidéu, 3 a 7 de abril de 2009.

Recebimento dos originais: $16 / 08 / 2015$

Aceitação para publicação: 08/12/2015 